\title{
BMJ Open Twenty-year time trends in hypertension prevalence in Yi people of China: three successive cross-sectional studies, 1996-2015
}

\author{
Jia Zhang, ${ }^{1}$ Shaoping Wan, ${ }^{2}$ Biao Zhang, ${ }^{1}$ Fen Dong, ${ }^{3}$ Li Pan, ${ }^{1}$ Wuli Yihuo, ${ }^{4}$ \\ Haiying Gong, ${ }^{5}$ Fang Yang, ${ }^{6}$ Guodong Xu, ${ }^{3}$ Zheng Li, ${ }^{6}$ Guoju Li, ${ }^{1}$ Yanlong Li, ${ }^{1}$ \\ Xiaoyang Wang, ${ }^{1}$ Guangliang Shan ${ }^{1}$
}

To cite: Zhang J, Wan S, Zhang B, et al. Twenty-year time trends in hypertension prevalence in Yi people of China: three successive cross-sectional studies, 1996-2015. BMJ Open 2018;8:e022714. doi:10.1136/ bmjopen-2018-022714

- Prepublication history for this paper is available online. To view these files, please visit the journal online (http://dx.doi org/10.1136/bmjopen-2018022714).

Received 6 March 2018 Revised 24 August 2018 Accepted 31 August 2018

Check for updates

(C) Author(s) (or their employer(s)) 2018. Re-use permitted under CC BY-NC. No commercial re-use. See rights and permissions. Published by BMJ.

For numbered affiliations see end of article.

Correspondence to Professor Guangliang Shan; guangliang_shan@163.com

\section{ABSTRACT}

Objective To explore the trend of hypertension prevalence and related factors in Yi people from 1996 to 2015.

Methods Three successive cross-sectional surveys were conducted in Liangshan Yi Autonomous Prefecture in 1996, 2007 and 2015, respectively. A total of 8448 participants aged 20-80 years (5040 Yi farmers, 3408 Yi migrants) were included in final analysis.

Results Overall, the age-standardised prevalence of hypertension in migrants was significantly higher than in farmers. Furthermore, the age-standardised prevalence rates increased from $10.1 \%$ to $15.3 \%$ to $19.6 \%$ in Yi migrants and from $4.0 \%$ to $6.3 \%$ to $13.1 \%$ in Yi farmers during 1996 to 2007 to 2015. The highest 2015-to-1996 ratio of age-standardised hypertension prevalence was in male farmers (ratio=4.30), whereas despite the highest prevalence of hypertension, the equivalent figure in male migrants was 1.57. The older age, overweight and obesity were persistent risk factors of hypertension in three periods. After adjusted for age and body mass index, the difference of hypertension prevalence between 1996 and 2015 then vanished in male migrants $(\mathrm{OR}=1.335 ; 95 \% \mathrm{Cl}$ : 0.884 to 2.015$)$ and female farmers $(\mathrm{OR}=1.267 ; 95 \% \mathrm{Cl}$ : 0.590 to 2.719 ). The disparities of hypertension prevalence between Yi migrants and farmers were not statistically significant in all subgroups when adjusted for age, body mass index and education.

Conclusions Over the past two decades, the hypertension prevalence in Yi people has significantly increased.

Yi migrants were more likely to be hypertensive than

Yi farmers which was predominantly driven by the discrepancy of body mass index between them.

\section{INTRODUCTION}

Hypertension, also known as high or raised blood pressure (BP), is the predominant risk factor for heart disease, stroke and renal failure which are leading causes of death. ${ }^{1-3}$ The increasing trends of hypertension prevalence can be observed both in high-income countries, ${ }^{45}$ as well as in low-income and middle-income countries. ${ }^{6-8}$
Strengths and limitations of this study

- The present study was first designed to explore the hypertension prevalence trend of Yi people during last two decades.

- These three population-based successive Yi migrant studies were implemented by identical team and followed the same protocol.

- Under the context of rapid urbanisation, the ruralurban migration effect on health was estimated by comparing hypertension prevalence between Yi migrants and Yi farmers.

- The unclear temporal relationship between body mass index and hypertension is due to inherent weakness of cross-sectional studies, and have been heatedly debated in epidemiological studies.

- Furthermore, important confounding factors possibly associated with the increasing trend in hypertension prevalence in Yi people, such as nutrition and environmental changes, were not evaluated in the present study.

We live in a rapidly changing environment. Throughout the world, human health is being shaped by the same powerful forces: demographic ageing, rapid urbanisation and the globalisation of unhealthy lifestyles. In general, rural-urban migration, as part of urbanisation, is considered a promoting factor for chronic diseases, ${ }^{9}$ and evidence shows that urbanisation is estimated to raise the BP of residents. ${ }^{10}$ In contemporary China, socioeconomic transformation at the beginning of the 21st century has led to rapid urbanisation and accelerated rural-urban migration $^{11}$ along with the phenomenon of increased mean BP that has been described among Chinese population. ${ }^{12-14}$

It is reported that hypertension prevalence in ethnic minorities is significantly higher than in Han. ${ }^{15}$ However, Yi people resided in Liangshan Yi Autonomous Prefecture located 
in Sichuan Province, Southwestern China used to be renowned for its low mean $\mathrm{BP}$ and prevalence of hypertension ${ }^{16}$ and had been undergoing immense scale ruralurban migration. ${ }^{17}$ Although a host of investigations about hypertension prevalence of Han people have been carried out, ${ }^{18-20}$ the data about trend of hypertension prevalence in Yi people is insufficient. Therefore, it is of great necessity to conduct relevant research to acknowledge the situation of hypertension in Yi people. Additionally, as the dramatic health transition resulted from rapid rural-urban migration, Yi people may encounter higher hypertension prevalence than before.

Accordingly, we conducted the Yi migrant study to assess the prevalence of hypertension by migration status and period; the association of hypertension with individual characteristics; the related factors that accounted for the discrepancy of hypertension prevalence among subgroups and periods.

\section{METHODS}

\section{Study design and participants}

The Yi people is a minority in China living in Liangshan Yi Autonomous Prefecture in Southern China, an area that covers about $60000 \mathrm{~km}$ and has roughly 5 million residents in which $52.5 \%$ are Yi people. The Yi people usually live in remote mountain districts at or $1500 \mathrm{~m}$ above sea level. Their main occupation is agriculture, and they are one of the most primitive societies in China. The Yi Migrant Study includes three cross-sectional studies conducted in Liangshan Yi Autonomous Prefecture in 1996, 2007 and 2015, respectively. The sampling procedures have been published previously in detail. ${ }^{21}{ }^{22}$ In the two previous periods, stratified cluster sampling was used to select participants from Xichang city, Butuo, Zhaojue, Jinyang, Puge and Xide counties. Due to the inevitably restrained accessibility, we only conducted our survey in Xichang city and Puge county in 2015.

The Yi farmers were defined as those whose parents are Yi people and had been lived in the countryside since birth. There are one to four county seats in each county. The Yi farmers were selected by stratified cluster sampling from areas around each county seat. Four villages were randomly selected from each area. In the last sampling stage, all the Yi farmers aged 20 years or over in the selected villages were surveyed. There are two types of $\mathrm{Yi}$ migrants, one are those who have been born in countryside and then have migrated into county or city for more than 1 year, the other are Yi people who have been born in county or city and have lived there until the survey. All Yi migrants' parents are Yi people. And because the number of the Yi migrants was relatively small, all of the Yi migrants (20 years of age and over) found in the selected counties and Xichang city were enrolled in the study.

Isolated from the outside world, the Yi farmers who live in high-mountain areas and mountainside areas have their own language and primitive lifestyle. There are only extremely steep and narrow paths leading to these villages which are several hours walking distance apart. Their main nutritional source are staple food such as potato, oat and buckwheats, and the living conditions are greatly backward. There is even no table for eating; almost all Yi farmers squat down to eat in 2015. The Yi migrants who live in the county or city with Han people have a much more western lifestyle. It is relatively convenient for them to acquire meat, fresh fruits and vegetables. And there is a great extent of improvement in their living conditions compared with Yi farmers. As described He $e t a l^{23}$ in their study, the Yi farmers began to migrate to counties and cities from remote mountain districts since the 1950s.

As the involvement of participants, local centres for disease control and prevention were responsible for the propagation and local governments took charge of the recruitment. In these three periods, the number of participants were 1664, 3768 and 3317, respectively. After excluded those who were out of the age bracket or lacking key variables such as $\mathrm{BP}$ and migration status, there were a total of 8448 Yi people in the final analysis (figure 1).

Data were collected by trained medical staff using standardised methods and identical examinations in 1996-2015, including a questionnaire for assessment of demographic characteristics and anthropometric measurements. In order to reduce the information bias, we conducted a two-stage questionnaire survey. First, participants completed the questionnaire with a trained medical staff. Then, there were several group leaders audit each questionnaire by randomly extracting some items.

\section{Measurements}

Both body height and weight were measured with the participants in light clothing and without shoes after an overnight fast. Body mass index (BMI) was defined as measured weight in kilograms divided by squared height in metres. There were four BMI categories: underweight defined as a BMI $<18.5 \mathrm{~kg} / \mathrm{m}^{2}$; normal weight, $18.5-23.9 \mathrm{~kg} / \mathrm{m}^{2}$; overweight, $24-27.9 \mathrm{~kg} / \mathrm{m}^{2}$; and obese, $\geq 28 \mathrm{~kg} / \mathrm{m}^{2}$.

Education was categorised as low (received only primary education or no education), middle (finished secondary school or high school) and high (graduated from college or university).

Physical activity was divided into three categories: (1) light: for example, office worker, salesperson and house worker; (2) middle: for example, driver, electrician and latheman; (3) heavy: for example, manual worker, steel worker and mineworker.

Smoking status was classified as never-smokers and eversmokers which included current smokers (having been regularly smoking at least one cigarette per day during the previous 6 months) and ex-smokers (once smoked but had quitted smoking for 6 months or longer). Alcohol consumption was divided into never-drinker and ever-drinker those who drank at least twice per month (more than $640 \mathrm{~mL}$ beer or $100 \mathrm{~mL}$ Chinese liquor, about $57 \mathrm{~g}$ alcohol) and had lasted for at least 6 months or stopped drinker. 


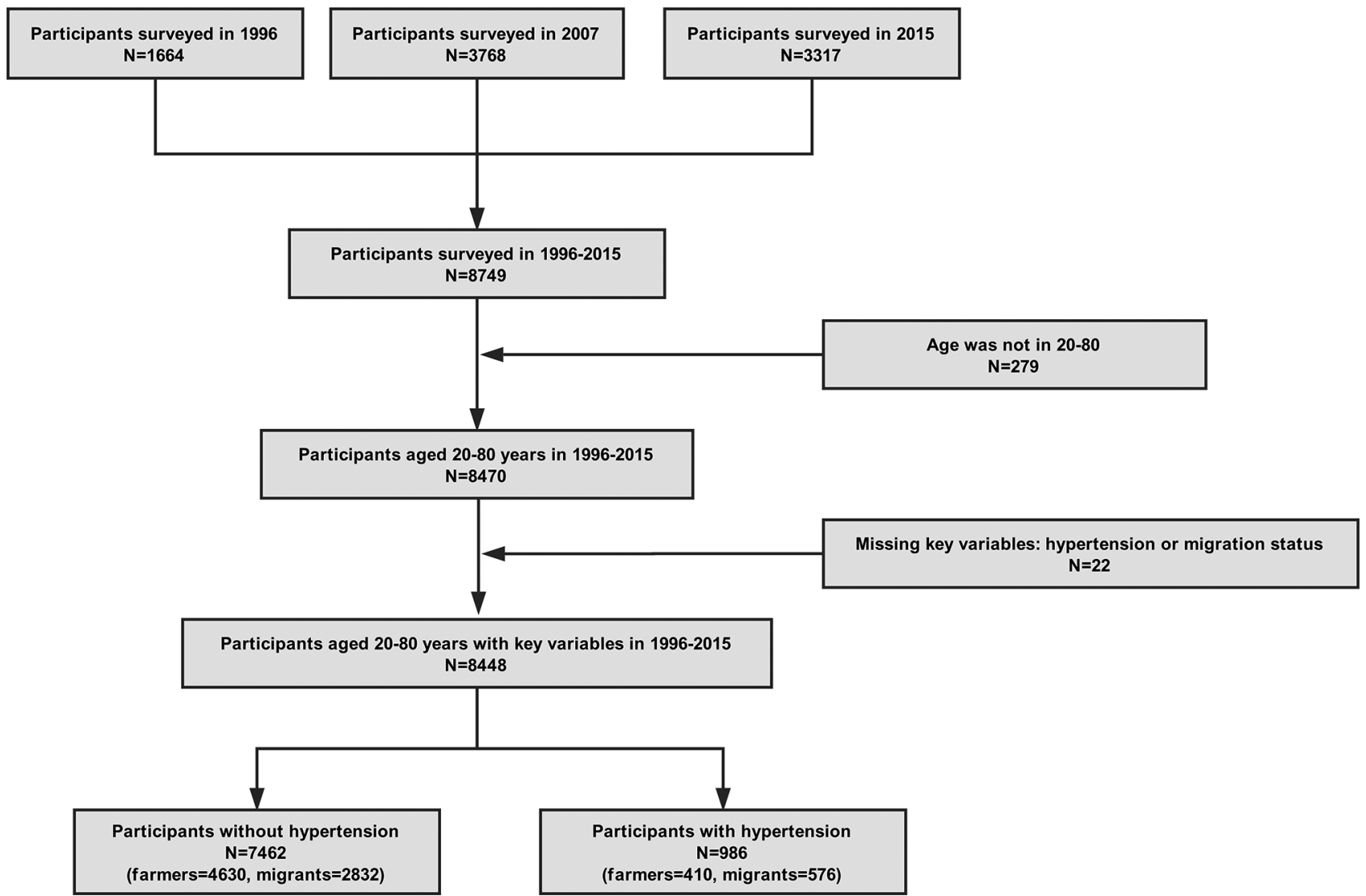

Figure 1 Flow diagram of Yi migrant study. Hypertension was defined as follows: individuals who reported having diagnosed hypertension, receiving blood pressure (BP)-lowering treatment or had an average measured systolic BP at least $140 \mathrm{~mm} \mathrm{Hg}$, diastolic BP at least $90 \mathrm{~mm} \mathrm{Hg}$ or both.

After an overnight fast, BP were measured by trained physicians using mercury sphygmomanometer in 1996 and Omron automatic digital BP measuring device (HEM-907) in 2007 and 2015. Appropriate BP cuff sizes were used for participants based on measurement of mid-arm circumference. BP was measured in the sitting position and on the right arm after a rest of at least $10 \mathrm{~min}$ and had not smoked, exercised or eaten. Both systolic BP (SBP) and diastolic BP (DBP) were recorded. The mean of three measurements was used for all analyses. The definition for hypertension was as follows: individuals who reported having diagnosed hypertension, receiving BP-lowering treatment or had an average measured SBP at least $140 \mathrm{~mm} \mathrm{Hg}$, DBP at least $90 \mathrm{~mm} \mathrm{Hg}$ or both. ${ }^{24}$

\section{Statistical analysis}

Summary results are presented as percentages (with numbers) for categorical variables and mean (and SD) for the continuous variables. As for trend analysis, simple linear regression model and Cochran-Armitage trend test were used to explore trends of age and male percentage during 1996-2015, respectively. For continuous variable, BMI, using multiple linear regression model to adjust for age and sex. In this model, BMI was the dependent variable and age, sex and period were independent variables. For multinomial variables with ordered categories, such as BMI categories and education, the cumulative logistic model was used to calculate the $\mathrm{p}$ value of trend analysis; in this model, BMI categories or education was the dependent variable and age, sex and period were independent variables. For binary variable, hypertension, we fitted a binary logistic regression model, in which hypertension was the dependent variable and age, sex and period were independent variables, to conduct the trend analysis. All generalised linear models identify the period as continuous variable instead of dummy variables, and its $p$ value in the model represents the result of trend analysis.

Direct standardisation was performed using China population age structure from the Sixth National Population Census in 2010 by SAS V.9.4 using 'stdrate' commend, and the geometric progression method was used to predict the age-standardised prevalence of hypertension in Yi people by 2030.

To explore the related factors of hypertension in each period, we used multiple logistic regression model to calculate the OR and the $95 \%$ CI; in which age was the continuous variable while sex, BMI groups, education, activities, smoking and drinking were categorical variables.

Finally, we developed a set of binary logistic regression models to identify the reasons behind the disparities of hypertension risk between different periods and different migration status. In period models, period was treated 
Table 1 Characteristics of participants by migration status and period, Yi migrant study, 1996-2015

\begin{tabular}{|c|c|c|c|c|c|c|c|c|}
\hline \multirow[b]{2}{*}{ Variable } & \multicolumn{4}{|l|}{ Farmers } & \multicolumn{4}{|l|}{ Migrants } \\
\hline & $\begin{array}{l}1996 \\
n=723\end{array}$ & $\begin{array}{l}2007 \\
n=2351\end{array}$ & $\begin{array}{l}2015 \\
n=1966\end{array}$ & P for trend & $\begin{array}{l}1996 \\
n=679\end{array}$ & $\begin{array}{l}2007 \\
n=1393\end{array}$ & $\begin{array}{l}2015 \\
n=1336\end{array}$ & $P$ for trend \\
\hline Mean age, years (SD) & $35.0(12.7)$ & $39.4(12.0)$ & $45.3(12.8)$ & $<0.0001^{*}$ & $37.9(11.2)$ & $39.6(12.0)$ & $48.3(14.4)$ & $<0.0001^{*}$ \\
\hline Mean BMI, kg/m² (SD) & $20.3(2.1)$ & $21.4(2.6)$ & $22.3(3.6)$ & $<0.0001 \dagger$ & $22.4(3.0)$ & $23.5(3.7)$ & $24.4(3.8)$ & $<0.0001 \dagger$ \\
\hline Male, \% (N) & $63.5(459)$ & $47.1(1107)$ & $33.8(664)$ & $<0.0001 \ddagger$ & $57.1(388)$ & $57.3(798)$ & $33.1(442)$ & $<0.0001 \ddagger$ \\
\hline BMI categories, \% $(\mathrm{N}) \S$ & & & & $<0.0001 \rrbracket$ & & & & $<0.0001 \rrbracket$ \\
\hline Normal weight (BMI 18.5-23.9) & $81.8(588)$ & $78.4(1837)$ & $58.3(1133)$ & & $63.4(428)$ & $51.6(718)$ & $42.3(560)$ & \\
\hline Overweight (BMI 24-27.9) & $2.5(18)$ & $10.6(248)$ & $21.8(423)$ & & $23.7(160)$ & $30.1(418)$ & $35.4(468)$ & \\
\hline Obesity (BMI $\geq 28$ ) & $0.4(3)$ & $1.7(39)$ & $7.1(138)$ & & $4.6(31)$ & $11.1(155)$ & $17.4(230)$ & \\
\hline Education, \% (N)§ & & & & $<0.0001 \rrbracket$ & & & & $<0.0001 \rrbracket$ \\
\hline
\end{tabular}

${ }^{*} \mathrm{P}$ values were calculated by simple linear regression model in which age was the dependent variable and period was the independent variable.

†P values were calculated by multiple linear regression model in which BMI was the dependent variable and age, sex and period were independent variables.

$\ddagger P$ values were calculated by Cochran-Armitage trend test.

$\S$ Numbers do not sum up to the total due to missing data.

ПP values were calculated by cumulative logistic model in which BMI categories or education was the dependent variable and age, sex and period were independent variables.

${ }^{* \star} \mathrm{P}$ values were calculated by binary logistic regression model in which hypertension was the dependent variable and age, sex and period were independent variables.

BMI, body mass index.

as dummy variable and period=1996 was the reference group; in migration status models, Yi farmers was the reference group. The trend analyses were realised by identifying period as continuous variable in binary logistic regression models. $\mathrm{P}$ values $<0.05$ were considered statistically significant. All statistical analyses were conducted using SAS software, V.9.4 (SAS Institute).

\section{Patient and public involvement}

Patients were not involved in the study design or conduct of the study. The results of the survey were disseminated to study participants by physical examination reports in 1996 and 2007, and in 2015 we developed an application which could allow participants to search their results at any time by using mobile phones.

\section{RESULTS}

\section{Study population characteristics}

Table 1 displays the characteristics of $\mathrm{Yi}$ people and the unadjusted prevalence of hypertension within time periods by migration status. Over the three study periods, the prevalence of obesity rose from $0.4 \%$ to $7.1 \%$ in $\mathrm{Yi}$ farmers, and from $4.6 \%$ to $17.4 \%$ in Yi migrants. By 2015, the crude prevalence of hypertension had increased by $9.5 \%$ in farmers, and by almost $16 \%$ in migrants.

\section{Age-standardised prevalence of hypertension}

Figure 2A shows the trends of age-standardised hypertension prevalence, and figure 2B is the predicted prevalence of hypertension using geometric progression method. It is noticeable that the prevalence of hypertension in male migrants was by far the highest among these four groups in each period, from $14.3 \%$ to $19.2 \%$ to $22.5 \%$ (for all comparison, $\mathrm{p}<0.0001$ ), while the equivalent figure for female farmers was from $4.4 \%$ to $3.1 \%$ to $10.2 \%$ (for 1996 vs 2015, and 2007 vs $2015, \mathrm{p}<0.0001$; for 1996 vs $2007, \mathrm{p}=0.4792$ ) which almost the lowest hypertension prevalence in each period (figure 2A). Overall, from 1996 to 2015, these four groups saw a statistical increase in prevalence of hypertension $(p<0.0001$ for all groups).

And the biggest 2015-to-1996 ratio of age-standardised prevalence of hypertension was in male farmers (ratio=4.30) which meant this group had the fastest pace of hypertension increase, followed by female migrants $($ ratio $=2.81)$ and female farmers (ratio=2.32). Interestingly, despite the highest prevalence of hypertension, the 2015-to-1996 ratio of age-standardised prevalence of hypertension in male migrants was 1.57 , and it was the lowest growth rate. Accordingly, we predicted that, if the growth rates stayed steadily, male farmers would overtake male migrants to become the most prevalent hypertensive group in 2021, and female migrants would overtake 


\section{A}
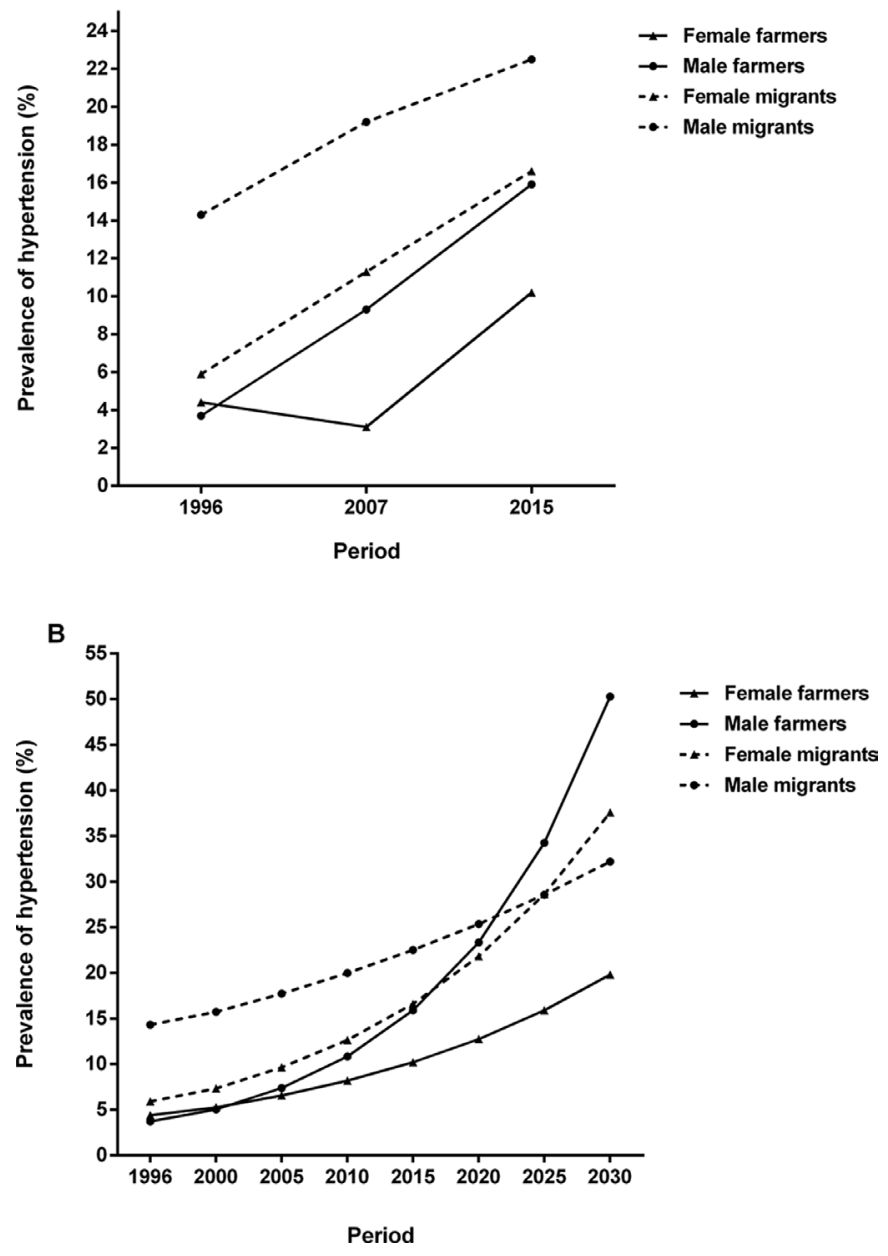

Figure 2 Age-standardised prevalence of hypertension and predicted prevalence of hypertension by gender and migration status, Yi migrant study, 1996-2015. (A) Age-standardised prevalence of hypertension by gender and migration status, Yi migrant study, 1996-2015. Agestandardised prevalence of hypertension was calculated by the direct method using the Chinese population age structure from the Sixth National Population Census in 2010. (B) Predicted prevalence of hypertension by gender and migration status, Yi migrant study, 1996-2015. Predicted prevalence of hypertension were calculated by the Geometric Progression Method.

male migrants in 2025 to become the second most prevalent hypertensive group (figure 2B).

\section{Related factors of hypertension and hypertensive discrepancy}

Figure 3 provides ORs for hypertension-related factors in each period. Across three periods, the higher hypertensive share traits such as much older and had higher BMI, but only in 2015 those who acquired high school education or higher were more likely to have hypertension than those whose education level were maximum to primary school (OR=1.524, 95\% CI: 1.038 to 2.236 ).

Table 2 shows ORs of the time period by different models. In model 1, the unadjusted results showed that both 2007 and 2015 had a significantly higher risk of hypertension versus 1996 among all subgroups. Model 2 in table 2 adjusted for age and BMI, the effect of period turned out to be not significant in male migrants (2007: $\mathrm{OR}=1.350$, 95\% CI: 0.923 to 1.974 ; 2015: OR=1.335, 95\% CI: 0.884 to 2.015 ) and female farmers (2007: OR=0.544, $95 \% \mathrm{CI}$ : 0.245 to 1.210 ; 2015 : $\mathrm{OR}=1.267,95 \%$ CI: 0.590 to 2.719 ), indicating that the increase of hypertension prevalence in these two groups over the 20-year period could be totally explained by the population ageing and upward trend of BMI, while the residual significant difference among period in female migrants (2007: $\mathrm{OR}=2.661,95 \%$ CI: 1.205 to 5.874 ; 2015: $\mathrm{OR}=3.158,95 \%$ CI: 1.474 to 6.765 ) and male farmers (2007: $\mathrm{OR}=1.763,95 \%$ CI: 1.025 to 3.032; 2015: $\mathrm{OR}=2.287,95 \%$ CI: 1.307 to 4.000$)$ suggested that ageing and increasing BMI just accounted for a portion of hypertension prevalence rise.

From 1996 to 2007 to 2015, there were significant increasing trends in the risk of hypertension among all groups when not adjusted for other variables $(p<0.0001$ for all groups), while after adjusted for age and BMI, only in male migrants the trend in risk of being hypertensive was insignificant $(\mathrm{p}=0.2277)$.

In order to investigate the reason behind the discrepancy in hypertension prevalence between migrants and farmers, table 3 shows the OR of migrant status (migrants vs farmers) by different models. For model 1, when not adjusted for other variables, we noticed that migrants were more likely had a higher risk of hypertension among all subgroups except the female in 1996 ( $\mathrm{OR}=0.905,95 \%$ CI: 0.335 to 2.445$)$. There was no significant change after adjusting for age in model 2. Model 3 in table 3 adjusted for age and BMI, and there was no significantly different risk of hypertension between migrants and farmers for males in 2007 (OR=1.097, 95\% CI: 0.782 to 1.539$)$ and 2015 (OR=0.992, 95\% CI: 0.674 to 1.460$)$, and for females in 2015 (OR=1.126, $95 \%$ CI: 0.834 to 1.521$)$. In model 4 , after adjusted for age, BMI and education, the discrepancy between migrants and farmers in males in 1996 (OR=1.753, 95\% CI: 0.729 to 4.217) and females in 2007 $(\mathrm{OR}=1.295,95 \%$ CI: 0.711 to 2.357$)$ had disappeared.

Therefore, we may conclude that for males in 2007 and 2015 and females in 2015, the higher risk of hypertension in migrants was resulted from ageing and increasing BMI, whereas for males in 1996 and females in 2007, not only these two factors mentioned above but also the education contributed to the remainder higher risk of hypertension in migrants.

\section{DISCUSSION}

Rising number of migrants, coupled with population ageing, have elicited major concern over the consequences of lifestyle changes for chronic diseases. Recent increases in longevity may not have been accompanied by a compression of morbidity, resulting in more years spent in an unhealthy state. ${ }^{25}$ Our prior work showed that the mean $\mathrm{BP}$ of Yi farmers did not rise or rarely rose with age after puberty, and essential hypertension was absent. ${ }^{16}$ In 


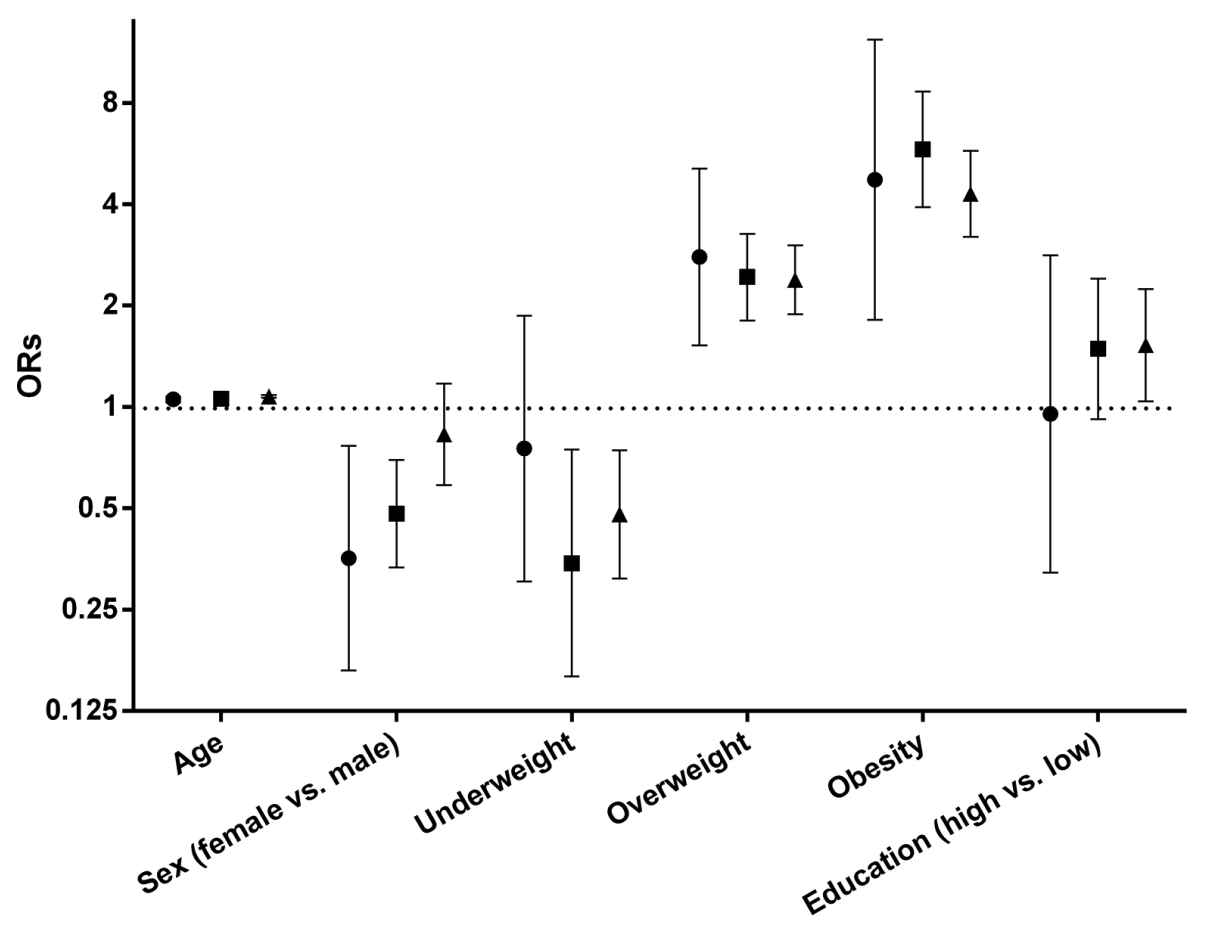

- 1996

- 2007

\ 2015

Variables

Figure 3 Relative Odds and $95 \% \mathrm{Cl}$ of hypertension-related factors by period, Yi migrant study, 1996-2015. The ORs were adjusted for age, sex, smoking, drinking, education and activities. Variables which did not have statistical significance of hypertension in any period were not shown.

this study, we have investigated whether this unusually hypertensive profile of Yi people has continued.

We found that the prevalence of hypertension in Yi people had seen a dramatic increase over the past 20 years, but was still lower than the whole country when compared with studies which used the same standardised population structure. ${ }^{26-29}$ What is noteworthy is that $\mathrm{Yi}$ migrants have had higher risk of hypertension than Yi farmers in each period, while the discrepancy in prevalence of hypertension between migrants and farmers is

Table 2 Odds for hypertension in 2015, 2007 relative to odds of hypertension in 1996, by migration status and gender

\begin{tabular}{|c|c|c|c|c|c|c|c|c|}
\hline \multirow[b]{2}{*}{ Group } & \multirow[b]{2}{*}{ Model } & \multirow[b]{2}{*}{ Period } & \multicolumn{2}{|l|}{ Male } & \multirow[b]{2}{*}{ P for trend } & \multicolumn{2}{|c|}{ Female } & \multirow[b]{2}{*}{ P for trend } \\
\hline & & & OR & $95 \% \mathrm{Cl}$ & & OR & $95 \% \mathrm{Cl}$ & \\
\hline \multirow[t]{4}{*}{ Migrants } & Model 1* & 1996 & 1 & & $<0.0001 \dagger$ & 1 & & $<0.0001 \dagger$ \\
\hline & & 2015 & 3.411 & 2.362 to 4.925 & & 8.731 & 4.243 to 17.966 & \\
\hline & Model 2ł & 1996 & 1 & & $0.2277 \S$ & 1 & & $0.0048 \S$ \\
\hline & & 2015 & 1.335 & 0.884 to 2.015 & & 3.158 & 1.474 to 6.765 & \\
\hline \multirow[t]{4}{*}{ Farmers } & Model 1* & 1996 & 1 & & $<0.0001 \dagger$ & 1 & & $<0.0001 \dagger$ \\
\hline & & 2007 & 2.385 & 1.405 to 4.047 & & 0.981 & 0.452 to 2.131 & \\
\hline & & 2015 & 5.561 & 3.293 to 9.391 & & 3.793 & 1.836 to 7.835 & \\
\hline & Model 2ł & 1996 & 1 & & $0.0033 \S$ & 1 & & $0.0007 \S$ \\
\hline
\end{tabular}

*Model 1 did not adjust for other variables.

†P values were calculated by binary logistic regression model in which hypertension was the dependent variable and period was the independent variable.

$\ddagger$ Model 2 adjusted for age and BMI.

$\S \mathrm{P}$ values were calculated by binary logistic regression model in which hypertension was the dependent variable and age, BMI and period were independent variables.

BMI, body mass index. 
Table 3 Odds for hypertension in migrants relative to odds for hypertension in farmers, by gender and period

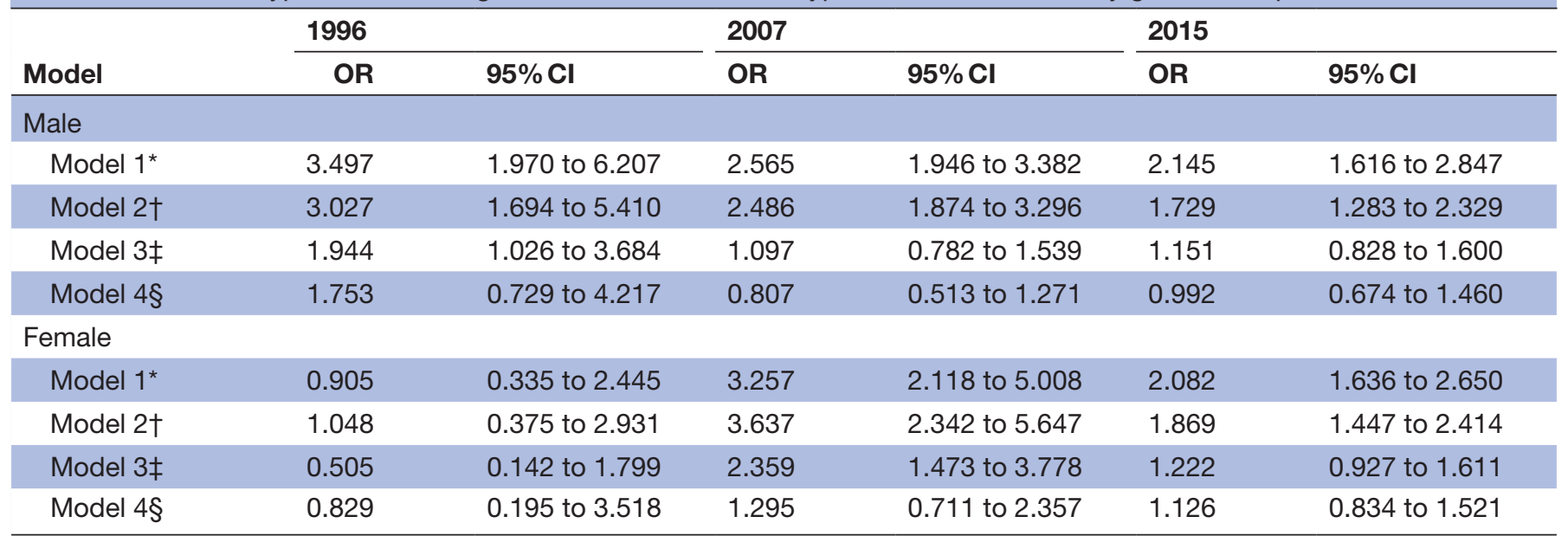

${ }^{*}$ Model 1 did not adjust for other variables.

†Model 2 adjusted for age.

¥Model 3 adjusted for age and BMI.

§Model 4 adjusted for age, BMl and education.

$\mathrm{BMI}$, body mass index.

narrowing. Li et al had found that the urban-rural gap in hypertension prevalence gradually narrowed during the period $1993-2011^{30}$ which might be attributed to the suboptimal hypertension detection and preventive care service utilisation in rural adults. ${ }^{31}$ The Third National Health Services Survey in China ${ }^{32}$ indicates that rural minority Chinese use significantly less health services, including visiting physicians and hospital utilisation, than urban minority Chinese, and the result that hypertension is much more prevalent in Yi migrants than Yi farmers is also consistent with many other research. The Kenyan Luo migration study conducted by Poulter et $a l^{33}$ confirmed that the BP of migrants who left a traditional rural community to settle in an urban one were significantly higher than that of control. In addition, as our country has witnessed numerous rural-urban migration, ${ }^{34}$ there are quantitative relation between the migration and hypertension. Similarly, India is a rapidly urbanising country which encountered the same problems as China. A cross-sectional study ${ }^{35}$ of neo-migrants and settled-migrants (at least 10 years residence) in the city of Delhi found that settled-migrants had higher prevalence of hypertension than neo-migrants.

In our study, we detected that ageing and increasing BMI could largely account for the rise in prevalence of hypertension both between different periods and different migration status. Higher BMI definitely increases the risk of hypertension, ${ }^{36}$ and even the impact of overweight and obesity on hypertension has risen significantly over time. ${ }^{37}$ The crude prevalence of overweight and obesity had undoubtedly increased across the 20-year period in Yi people which was consistent with Shan $e t a l$ s study, and had revealed that both Yi migrants and Yi farmers had a distinct increase in prevalence of overweight and obesity during 1996-2007. ${ }^{22}$ A cross-sectional study indicated that Yi people in China exhibited a strikingly lower prevalence of overweight and obesity than that observed in populations of Western countries, and overweight and obesity figures were $21.7 \%$ and $7.1 \%$, respectively, in $2008 .{ }^{38}$ Additionally, the disparity in the prevalence of overweight/ obesity between urban and rural areas was narrowing since $2000^{39}$ which could also interpret the declining trend of gap in hypertension between Yi migrants and Yi farmers. However, even though adjusted for age and BMI, there still has significant difference of hypertension prevalence between 2015 and 1996 in female migrants and male farmers. It might seem that some uninvolved factors, such as diet and economy, are responsible for the remaining risk of hypertension in these two groups. China Health and Nutrition Survey indicated that there was a dramatic change in dietary pattern in the past two decades, especially the steep increase of the 'Modern' pattern, while the 'Traditional' pattern was stable over the study period, which meant that nowadays people were more likely to consume processed food with refined carbohydrates, added salt and sweetener, edible oils, animal-resource foods, while the average intake of cereal, fresh fruits and vegetables had decreased. ${ }^{40} 41$ Yi farmers who have preserved their own language and primitive lifestyle rarely eat meat except during the Yi New Year in December, and their main crops are potatoes, oats and buckwheats. ${ }^{16}$ With economic growth and large-scale migration, Yi people consume more modern foods which contain high levels of sugar, salt and fat, especially in Yi migrants. ${ }^{42}$ Therefore, we suppose that changes in $\mathrm{Yi}$ people's diet would probably account for a part of hypertensive risk.

Distinguish from other research, these three successive Yi migrant studies were almost completed by one stable team, only a few students renewed, and this high consistency guarantees the comparability between different periods. Furthermore, it is the first time to explore the 
hypertension prevalence trend of Yi people by such a long time span and in such a large scale. We also investigated the reasons of hypertension discrepancy both between different periods and different groups which would provide local government with relatively practical recommendations for the prevention and treatment of hypertension.

There are several limitations that merit comment. At first, our study did not analyse the Han people who resided at the same urban areas with Yi migrants in the same period. Thus, the comparison to determine which is relatively important between environment and gene is not able to be accomplished. Furthermore, the tool of measuring BP is not consistent among three periods. We used the mercury sphygmomanometer in 1996 and Omron automatic digital BP measuring device in 2007 and 2015. It might have slight bias among the measurements, but the automatic device had been calibrated with the mercury sphygmomanometer before measurements, and there are studies that have validated the accuracy and validation of Omron HEM-907. ${ }^{43-45}$ Lastly, our research belongs to cross-sectional study. It might seem unpersuasive to identify causal effect between BMI and hypertension, and selection bias probably decrease the comparability between different periods. Therefore, it is fairly necessary to conduct prospective cohort study in $\mathrm{Yi}$ people to investigate the association between increased $\mathrm{BMI}$ and the rise of hypertension. As for selection bias, we used standardised prevalence of hypertension and adjusted the 'period' by logistic regression model to eliminate the difference of demographic characteristics among three surveys and improve the comparability.

In conclusion, China has undergone unprecedented-scale urbanisation and rural-urban migration, which is accompanied by rigorous challenges of public health during the past two decades. Because of the rapid increase in hypertension prevalence both in Yi migrants and farmers, effective prevention, detection, treatment and control of hypertension continue to be important goals for health policy, public health and medical care decision-makers, as well as individuals who have higher risk of hypertension. It should be noted that although Yi migrants were more likely to be hypertensive than Yi farmers in each period, the growth rates of these two groups were exactly reverse. In general, ageing and increasing BMI could largely account for the rise in prevalence of hypertension both between different periods and different migration status. Nevertheless, it is necessary to conduct a cohort study in rural-urban migrants to explore the causal effect. These results put the onus on the governments and assist the government to tailor prevention and treatment programmes for high-risk population in Yi people.

\section{Author affiliations}

${ }^{1}$ Department of Epidemiology and Statistics, Institute of Basic Medical Sciences, Chinese Academy of Medical Sciences, School of Basic Medicine, Peking Union Medical College, Beijing, China
${ }^{2}$ Sichuan Provincial Hospital, Chengdu, Sichuan, China

${ }^{3}$ Institute of Clinical Medical Sciences, China-Japan Friendship Hospital, Beijing, China

${ }^{4}$ Department for Chronic Noncommunicable Diseases Control, Puge County Center for Disease Control and Prevention, Xichang, Sichuan, China

${ }^{5}$ Department for Infections Diseases and Endemic Diseases Control, Fang Shan Center for Disease Control and Prevention, Beijing, China

${ }^{6}$ Xichang Municipal Center for Disease Control and Prevention, Xichang, Sichuan, China

Acknowledgements Special thanks are for Professor Guanqing He for his great contribution to the project initiation. We would like to thank Professors Hui Li and Konglai Zhang from the Institute of Basic Medical Sciences, CAMS, School of Basic Medicine, PUMC, Beijing, China and physicians from Liangshan Yi Autonomous Prefectural Center for Disease Control and Prevention, Xichang, Sichuan province, China for providing assistance to the study. We thank all the participants, staff and research fellows in the Yi Migrant Study for their long-term contribution to the study.

Contributors JZ participated in the data collection and drafted the manuscript. SW, WY, FY, ZL participated in the data collection. BZ, FD, LP, HG, GX, GL, YL, XW, GS participated in the design of the study and undertook statistical analyses. All authors were involved in writing the paper and had final approval of the submitted version.

Funding This study was supported by the National Natural Science Foundation, grant number 81273158 from the Ministry of Science and Technology, Beijing, People's Republic of China.

Competing interests None declared.

Patient consent Obtained.

Ethics approval Bioethics Committee of the Institute of Basic Medical Sciences, Chinese Academy of Medical Sciences (No. 033-2012), Beijing.

Provenance and peer review Not commissioned; externally peer reviewed.

Data sharing statement № additional data are available.

Open access This is an open access article distributed in accordance with the Creative Commons Attribution Non Commercial (CC BY-NC 4.0) license, which permits others to distribute, remix, adapt, build upon this work non-commercially, and license their derivative works on different terms, provided the original work is properly cited, appropriate credit is given, any changes made indicated, and the use is non-commercial. See: http://creativecommons.org/licenses/by-nc/4.0/.

\section{REFERENCES}

1. Mozaffarian D, Benjamin EJ, Go AS, et al. Heart disease and stroke statistics-2016 update: a report from the American Heart Association. Circulation 2016;133:E38-E360.

2. Huang Y, Su L, Cai X, et al. Association of all-cause and cardiovascular mortality with prehypertension: a meta-analysis. Am Heart J 2014;167:160-8.

3. Kannel WB. Elevated systolic blood pressure as a cardiovascular risk factor. Am J Cardiol 2000;85:251-5.

4. Egan BM, Zhao Y, Axon RN. US trends in prevalence, awareness, treatment, and control of hypertension, 1988-2008. JAMA 2010;303:2043-50.

5. Padwal RS, Bienek A, McAlister FA, et al. Epidemiology of hypertension in Canada: an update. Can J Cardiol 2016;32:687-94.

6. Gupta R. Trends in hypertension epidemiology in India. J Hum Hypertens 2004;18:73-8.

7. Ibrahim MM, Damasceno A. Hypertension in developing countries. Lancet 2012;380:611-9.

8. NCD Risk Factor Collaboration (NCD-RisC). Worldwide trends in blood pressure from 1975 to 2015: a pooled analysis of 1479 population-based measurement studies with $19 \cdot 1$ million participants. Lancet 2017;389:37-55.

9. Gong P, Liang S, Carlton EJ, et al. Urbanisation and health in China. Lancet 2012;379:843-52.

10. Chan F, Adamo S, Coxson P, et al. Projected impact of urbanization on cardiovascular disease in China. Int $\mathrm{J}$ Public Health 2012;57:849-54.

11. Mou J, Griffiths SM, Fong H, et al. Health of China's rural-urban migrants and their families: a review of literature from 2000 to 2012. Br Med Bull 2013;106:19-43. 
12. Dong $B$, Wang $Z$, Song $Y$, et al. Understanding trends in blood pressure and their associations with body mass index in Chinese children, from 1985 to 2010: a cross-sectional observational study. BMJ Open 2015;5:e009050.

13. Wang Z, Wu Y, Zhao L, et al. Trends in prevalence, awareness, treatment and control of hypertension in the middle-aged population of China, 1992-1998. Hypertens Res 2004;27:703-9.

14. Zhao Y, Yan H, Marshall RJ, et al. Trends in population blood pressure and prevalence, awareness, treatment, and control of hypertension among middle-aged and older adults in a rural area of Northwest China from 1982 to 2010. PLoS One 2013;8:e61779-491.

15. Gu H, Li W, Yang J, et al. Hypertension prevalence, awareness, treatment and control among Han and four ethnic minorities (Uygur, Hui, Mongolian and Dai) in China. J Hum Hypertens 2015;29:555-60.

16. He J, Tell GS, Tang YC, et al. Effect of migration on blood pressure: the Yi People Study. Epidemiology 1991;2:88-97.

17. Statistical information of liangshan. Http://tjj.Lsz.Gov.Cn/ (accessed 4 Nov 2016)

18. Wang J, Ning X, Yang L, et al. Trends of hypertension prevalence, awareness, treatment and control in rural areas of northern China during 1991-2011. J Hum Hypertens 2014;28:25-31.

19. Cai L, Liu A, Zhang L, et al. Prevalence, awareness, treatment, and control of hypertension among adults in beijing, china. Clin Exp Hypertens 2012;19:159-68.

20. Zhao Y, Lu F, Sun H, et al. Trends in hypertension prevalence, awareness, treatment, and control rates in Shandong Province of China. J Clin Hypertens 2012;14:637-43.

21. Wang $B$, Wei $D$, Wang $C$, et al. Prevalence of dyslipidemia and associated factors in the Yi farmers and migrants of Southwestern China. Atherosclerosis 2012;223:512-8.

22. Shan G, Wei D, Wang C, et al. Trends of overweight and obesity in $Y_{i}$ people between 1996 and 2007: an Yi migrant study. Biomed Environ Sci 2011;24:467-74.

23. He J, Klag MJ, Whelton PK, et al. Migration, blood pressure pattern, and hypertension: the Yi Migrant Study. Am J Epidemiol 1991;134:1085-101.

24. Jones DW, Hall JE. Seventh report of the joint national committee on prevention, detection, evaluation, and treatment of high blood pressure and evidence from new hypertension trials. Hypertension 2004;43:1-3.

25. Crimmins EM. Lifespan and healthspan: past, present, and promise. Gerontologist 2015;55:901-11.

26. Wang JG, Li Y. Characteristics of hypertension in the Chinese population. Curr Hypertens Rep 2012;14:410-5.

27. Li D, Lv J, Liu F, et al. Hypertension burden and control in mainland China: Analysis of nationwide data 2003-2012. Int J Cardiol 2015;184:637-44.

28. Qi SF, Zhang B, Wang HJ, et al. Prevalence of hypertension subtypes in 2011 and the trends from 1991 to 2011 among Chinese adults. $J$ Epidemiol Community Health 2016;70:444.
29. Lu J. Prevalence, awareness, treatment, and control of hypertension in china data from 1.7 million adults in a population-based screening. The Lancet 2017.

30. Li J, Shi L, Li S, et al. Urban-rural disparities in hypertension prevalence, detection, and medication use among Chinese Adults from 1993 to 2011. Int J Equity Health 2017;16:50.

31. Liu X, Li N, Liu C, et al. Urban-rural disparity in utilization of preventive care services in China. Medicine 2016;95:e4783

32. Liu M, Zhang Q, Lu M, et al. Rural and urban disparity in health services utilization in China. Med Care 2007;45:767-74.

33. Poulter NR, Khaw KT, Hopwood BE, et al. The Kenyan Luo migration study: observations on the initiation of a rise in blood pressure. BMJ 1990;300:967-72.

34. Peng X. China's demographic history and future challenges. Science 2011;333:581-7.

35. Kusuma Y, Gupta S, Pandav C. Migration and hypertension: a crosssectional study among neo-migrants and settled-migrants in Delhi, India. Asia Pac J Public Health 2009;21:497-507.

36. Lyall DM, Celis-Morales $\mathrm{C}$, Ward J, et al. Association of body mass index with cardiometabolic disease in the UK biobank: a mendelian randomization study. JAMA Cardiol 2017;2:882-9.

37. Nagai M, Ohkubo T, Murakami $\mathrm{Y}$, et al. Secular trends of the impact of overweight and obesity on hypertension in Japan, 1980-2010. Hypertens Res 2015;38:790-5.

38. Gao Y, Ran XW, Xie XH, et al. Prevalence of overweight and obesity among Chinese Yi nationality: a cross-sectional study. BMC Public Health 2011:11:919.

39. Wildman RP, Gu D, Muntner P, et al. Trends in overweight and obesity in Chinese adults: between 1991 and 1999-2000. Obesity 2008;16:1448-53.

40. Li M, Shi Z. Dietary pattern during 1991-2011 and its association with cardio metabolic risks in Chinese adults: the China health and nutrition survey. Nutrients 2017;9:1218.

41. Zhai $\mathrm{F}$, Wang $\mathrm{H}$, Du S, et al. Prospective study on nutrition transition in China. Nutr Rev 2009;67:S56-61.

42. Zhou J, Huang $\mathrm{C}, \mathrm{Xu} \mathrm{Y}$, et al. [The dietary patterns and nutritional status of adult Yi people in Liangshan autonomous region]. Wei Sheng Yan Jiu 2003;32:246-8.

43. White WB, Anwar YA. Evaluation of the overall efficacy of the Omron office digital blood pressure HEM-907 monitor in adults. Blood Press Monit 2001;6:107-10.

44. El Assaad MA, Topouchian JA, Darné BM, et al. Validation of the Omron HEM-907 device for blood pressure measurement. Blood Press Monit 2002;7:237-41.

45. Omboni S, Riva I, Giglio A, et al. Validation of the Omron M5-I, R5-I and HEM-907 automated blood pressure monitors in elderly individuals according to the International Protocol of the European Society of Hypertension. Blood Press Monit 2007;12:233-42. 